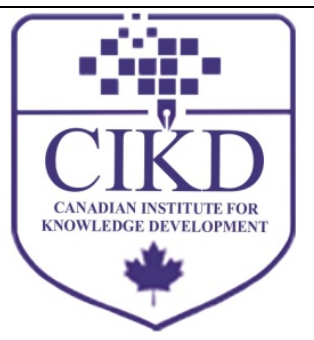

\title{
The Role of Work-Group Emotional Intelligence in Learning Organizations: a Case Study of the Greek Public Sector
}

\author{
Christina Arfara ${ }^{*}$, Athanasios Lamprakis, George Tsivos, Dr Irene Samanta
}

Piraeus University of Applied Sciences, Greece

\section{Keywords: \\ Work-group Emotional Intelligence, Learning Organization, Greek Independent Administrative Authorities}

\section{Received}

08 May 2018

Received in revised form 04 August 2018

Accepted

06 August 2018

Correspondence:

christinearfara@gmail.com

\begin{abstract}
The purpose of this paper is to explore the impact of Emotional Intelligence at work-group level on Learning Organization, examining five dimensions of L.O. according to Senge's model, within a framework of Greek Public Administration reform. The research was conducted among Greek Independent Administrative Authorities, a modern European institution that among others guarantees transparency and optimum performance, leading to upgraded public sector services. Our research is a quantitative research consisting of 257 valid questionnaires out of a sample of 300 employees. Our research highlights the strong correlation between Work-group Emotional Intelligence and Learning Organization. A constructive emotional climate affects the vision of the organization, while emotions have an impact on employees' attitudes/behaviours and on the learning process within the group as well as on the diffusion of information. Finally, our research demonstrated that emotional intelligence affects the personal improvement and development of employees. Managers should focus on developing more emotionally intelligent employees by cultivating an emotional environment that promotes positive behaviours, system thinking and group learning. Thus, the benefits generated can be identified at both individual and organizational level, including higher levels of employees' personal development, better communication processes and implementing the organization's vision.
\end{abstract}

(C)AIMI Journals

At a time when constant changes, innovation and creativity have become a common place in the job market, in order to survive organizations must learn to transform and adapt themselves to the new market environment. Organizations that accomplish such an adaptation, that means "adaptive organizations", are primarily what we usually call "learning organizations", namely 
organizations that have the ability to learn constantly. This presupposes the adoption by human resources of such learning methods that lead to the improvement of their knowledge and skills. It also means an even greater dependence of the organization on its work teams, as the learning process takes place between members and groups working within an organizational context, thus rendering the collective learning process a mainly social activity (Clarke, 2010; Ghosh, 2015).

Thus, the social skills and dexterities of members of the work teams contribute to a very high degree to such a process, since the process of learning in groups and organizations, as a social fact, ceases to be only a cognitive process and includes also a parallel emotional activity. Emotions and their management, both at individual and group level, constitute a set of social skills and dexterities that take place under the umbrella of the notion of "emotional intelligence". Emotional intelligence, which the bibliographical review shows to be strongly associated with a wide range of organizational behaviours, seems to be a leading factor in order for an organization to gain a sustainable competitive advantage in a changing environment (Clarke, 2010; Jordan, Ashkanasy, Hartel, \& Hooper, 2002).

Recent empirical research studies show that emotional intelligence, through the emotional climate created by the development of corresponding emotional skills within the groups that work together in an organization, positively correlates with every dimension of the "learning organization" and, as a result, with its long-term well-being (Hughes, 2000). Based on these bibliographical references, this empirical research will attempt to find out how emotional intelligence, at the work-group level, affects the learning process in these groups, and to what extent it relates to every dimension of the "learning organization". Our field of research was public organizations in Greece, since it is a pivotal challenge for Greece to transform and modernize its public administration, mainly through the process of continuous learning and adaptation to the new data created by the modern technological and scientific environment.

\section{Emotions and Emotional Intelligence}

Emotions are today recognized as an integral part of organizational life. Many types of work and their results depend heavily on emotional expressions such as passion, dedication, commitment, satisfaction, and sensitivity to the feelings and opinions of others. Even negative emotions, such as anger, reaction, frustration, and others, can be a precursor to preventing and correcting mistakes and bad practices within an organization (Gabriel \& Griffiths, 2002).

Recognizing, analysing and managing such emotions that occur and develop within an organization requires a deeper understanding of the subconscious dimensions that exist within an organization and is that ability that leads to emotional intelligence (Clarke, 2010). The concept of "emotional intelligence" was first defined by Salovey and Mayer (1990) as the ability of an individual to recognize their own and others' feelings, to distinguish positive effects from negative, and to be able to use them to direct their thoughts and actions.

Much later, Mayer and Salovey (1997) added that emotional intelligence differs from any other type of intelligence, since it refers to emotional management and thus describes the complex process that connects emotions to cognition. They refer to specific emotional abilities that connect emotion and cognition, which are: a) emotional awareness (refers to the recognition of the expression of emotions), b) emotional facilitation (relates to the extraction of 
information from emotions), c) emotional knowledge (refers to a deeper understanding and distinction of emotions), and d) emotional regulation (regards the proper management of emotions).

Earlier, Goleman (1995) had insisted on the complete differentiation of emotional intelligence from intellectual intelligence (IQ), defining "emotional intelligence" as the ability of individuals to understand their own feelings and the feelings of others in such a way that leads to their own motivation to better manage their relationships with others. In the model of emotional intelligence that Goleman developed, he embodied not only abilities but also personality characteristics of a person (such as empathy and motivation).

\section{Emotional Climate and Group Emotional Intelligence}

Until the 1980s, the concept of "emotions" was presented in the domain of "Organizational Behaviour" with a negative connotation, which was opposed to the cognitive and rational process that describes the context of organizational goals and the decision making within it. However, it soon became clear that the cognitive and emotional processes coexist and are interrelated in every work environment, since both are constitutive elements of the culture of an organization. It is now universally accepted that the emotional climate created in an organization runs through every dimension of the human interaction within it (Hughes, 2000; Tran, 1998).

Researchers have found, empirically, that emotions affect the motivation, efficiency and effectiveness of a work-group, mainly through the development of a group-level emotional climate. Group emotional intelligence is the predominant component of the development of this climate, which in turn maintains and promotes the corresponding team skills of emotional intelligence. These skills, just as at an individual level, are described by the ability of the workgroup to both diagnose the emotions of its members and manage collectively these emotions (Cote, 2007; Stubbs-Koman, \& Wolff, 2008).

The intensity of this collective emotional climate, either at a group-level or even at an organizational-level, is expressed through the dynamics characterizing the work-group level emotional intelligence in an organization. Emotional intelligence skills at a work-group level enable its members to turn not only positive but also negative emotions produced within the group into a comparative advantage. This advantage lies in the added value generated by the development of the social capital of the team, due to the good management of emotions at a work-group level (Clarke, 2010; Druskat \& Wolff, 2008).

Goleman (1998) says that only by enhancing group-level collective emotional intelligence, can an organization accomplish higher levels of collaboration, collective learning and effectiveness. Measuring emotional intelligence at an individual level can lead to misinformation when referring to the totality of an organization. There, the emphasis should be placed on the study of collective emotional intelligence and also on the calculation of the wider emotional climate, in order for us to be able to predict the effect that emotional intelligence exerts on the basic parameters of this organization (Goleman, 1998; Langley, 2000; Tran, 1998).

Managers of an organization must always take into account the importance and dynamics of emotions in all their work plans. It is clear that all the emotions experienced by workers in the 
workplace create a particular organizational emotional climate, which constitutes a central axis of working life and experience. How this emotional climate is created, maintained and then evolves has a tremendous impact on the functioning of the organization, its efficiency, performance and the job well-being of its members (Goleman, 1995; Tran, 1998).

\section{Learning Organization}

In the literature we come across various definitions for the organization that learns such as those of Chris Argyris, David Schön, Marsick and Watkins, etc. But the predominant theory is that of Senge, who is considered one of the patriarchs of the concept of Learning Organization, as through his book in 1990 he presented and analysed the above concept. Senge (1990, as cited in Jordan, 2004), argues that the learning organization is a group of people working collectively and seeking to improve themselves in order to achieve the desired outcomes. $\mathrm{He}$ refers to five (5) aspects of the concept of learning organization: personal mastery, mental models, systems thinking, team learning and building a shared vision (Bordeianu, Bordeianu, Harpenciuc, Bejinaru, \& Burciu, 2014; Daryani, Ardabili, \& Amini, 2014; Jordan, 2004; Public Service Learning Policy Directorate Canada, 2007).

Specifically, personal mastery refers to the commitment of the individual to the learning process of personal improvement and development of new skills. The positive results of this process are transferred and utilized by the organization in order to improve profitability. The process of learning at the individual level should be systematically supported and not derived exclusively from experience. At this point the role of the Human Resource Management Division (HRM) is particularly important, being required to meet not only the traditional functions of HRM but also the management of intellectual capital in order for every employee to recognize his or her strengths and weaknesses. Therefore, through proper guidance and good practices applied by HRM, every employee is able to recognize their personal limitations and to identify those fields where personal improvement and development can be achieved (Bordeianu et al., 2014; Jordan, 2004).

Mental models integrate existing behaviours and attitudes; they are the memory of the organization. In an organization that learns, these models should be identified, evaluated and changed by replacing any conflict behaviours with behaviours that foster teamwork, exchange of information and flexibility (Moynihan \& Landuyt, 2009; O'Keefee, 2002).

Team learning and fostering teamwork is also important in an organization; employees can learn, recognize and appreciate the offer of other colleagues and see the bigger picture of the organization. In successful teams, members exchange information, are open to new ideas, are open minded, receive help when needed and act independently in self-setting their goals, which are in alignment with the corporate strategy (Bergiel, Bergiel, \& Balsmeir, 2008; Clarke, 2010).

The fourth dimension, that of systems thinking, considers the organization as a separate entity in which all parts that compose it are interdependent and influence each other. It focuses on processes related to changes related either to processes or structures. Also, systems thinking requires the use of information systems and dissemination of information in time and to selected recipients (Jordan, 2004; Moynihan \& Landuyt, 2009; Public Service Learning Policy Directorate Canada, 2007).

Finally, a shared vision is crucial for an organization that learns as it creates a common 
identity that can be derived from the interaction between the top management level and employees. It is something that cannot be imposed but is cultivated by a learning culture. As well as the importance of developing a vision, also important is the way of communicating it. For this purpose, it is crucial that employees are given the opportunity to communicate with each other, to be encouraged by the synergies developed between them, to feel proud of their organization and to experience higher levels of job satisfaction and commitment. It is also very important that the managers encourage employees to ask questions, to challenge existing processes and disagree, thereby cultivating a learning culture, which is not critical of mistakes or failures but supportive and oriented to learn from them (Bordeianu et al., 2014; Garvin, Edmondson, \& Gino, 2008; Moynihan \& Landuyt, 2009; Public Service Learning Policy Directorate Canada, 2007).

\section{Getting Closer to an Organization that Learns}

Since the concept of learning has been considered as a strategic asset, the next step is how to transform the organization into an organization that learns. Every organization is different and, of course, there is not just one way to reach certain goals. But in this attempt there are some common factors. Initially we must clearly define our goal, where we want to go, in terms of norms, attitudes and behaviours of employees, as well as the learning processes within the group. At the same time certain conditions should be ensured in order that all the suggestions are oriented and aligned with the organization's strategy and its new vision to create an organization that continually learns, with a view to achieving optimal results (Barrados \& Mayne, 2003; Garvin et al., 2008; Yosoff, 2005).

Specifically, we need to cultivate an environment that supports the learning process. This means that emotional safety and security is provided to employees in order for them not to be afraid to express their opposition. New ways of working are tested while assessing their results. The new data is shared, collected and analysed in order to facilitate the flow and dissemination of information, and employees are encouraged not only to share the data but also to receive feedback. This essentially means the creation of a supportive work environment that fosters personal improvement and skills development, through clear and effective procedures and learning practices. An important role in learning processes is assigned to the training of employees, which should be periodic, updated and always adapted to the needs and characteristics of each individual employee (Barrados \& Mayne, 2003; Garvin et al., 2008; Public Service Learning Policy Directorate Canada, 2007).

\section{The Asset "Learning Organization" in the Public Sector: Reality or Myth?}

The relationship between a learning organization and employees becomes interactive and never-ending. As organizations in the modern and highly demanding environment perceive that their sustainability is directly related to the perception of employees regarding learning and to what extent they have embraced it. Employees in turn develop skills, evolve cognitively and emotionally and are led to greater adaptability to ensure a place in the operational / business world. Through their personal improvement and development, employees become more committed to the organization, the work environment becomes more interesting and progressive, resistance to change is overcome and innovation becomes more apparent. The 
people-oriented organization is a reality and the results are visible in the profitability of the organization (Chawla \& Renesch, 1995; Pedler, Burgogyne, \& Boydell, 1997).

As enterprises recognize the value of a learning organization and orientate towards their transformation, the question reasonably arises whether a public sector organization can learn. This is because they operate on different terms: private sector organizations operate under market conditions by focusing primarily on profit and economic data in general, the public sector on the other hand is trying to support and demonstrate its social values. Moreover, public organizations depend on the perceptions, interests, ideologies and values of the prevailing groups as well as on whether government wants to impose or interfere with sub-policies or to leave space for organizations to succeed through procedures and initiatives that they develop themselves (Visser \& Van der Togt, 2015).

According to Gilson, Dunleavy and Tinkler (2009), a public organization can learn from internal sources, i.e. through the memory developed by the organization and the experience of its employees, from citizens, and from researching and analysing the options and behaviour of partners-competitors. Learning can be achieved from top to bottom, by applying the necessary and logical controls (internal and external), and from criticism or advice that may be given through constructive dialogue.

On the other hand, the profile of civil servants in recent years has changed. A key feature is the high educational level, their intention for continuous personal growth and development. They want more flexibility from their managers, a positive people-management style, fairness, proper guidance and to be listened to (Yosoff, 2005). Therefore, it is difficult indeed for a political leadership to commit to all of the above but not impossible to cultivate and keep alive the vision of change and transformation of a public sector organization to become a first rate organization, in other words a learning organization can be a reality and not a myth.

\section{Work-group Emotional Intelligence and Learning Organization}

Studies show the direct influence of collective emotional intelligence at group-level on employees' performance and the effectiveness of the organization (Stubbs-Koman \& Wolff, 2008). Ghosh, Shuck and Petrosko (2012) show that the emotional intelligence of a group contributes positively to the ability of its members to work successfully for the good of the team and the organization. Other research studies indicate that working groups with a higher level of group emotional intelligence perform better than groups with a lower level group emotional intelligence (Stubbs-Koman \& Wolff, 2008). Jordan et al. (2002) demonstrated empirically that emotional management skills, at group level, contribute to increasing the efficiency of the group. These skills reach an even higher level when they are developed and strengthened through learning processes, both at individual and team level (Jordan et al., 2002).

At individual level, emotional intelligence is the key factor for a person to acquire skills to effectively deal with the daily challenges in the workplace and thus help to improve personal and interpersonal skills. People with high emotional IQ can better communicate their ideas, their intentions and goals are clear, they are positive, sensitive, and eager to learn from mistakes or omissions, showing a high degree of adaptability. These features are proved to be very important for the contemporary working environment. At a higher hierarchical level, emotionally intelligent managers are less prone to negative behaviours, have strategies to tackle 
difficult situations and are able to avoid poor decision-making styles (Furnham, 2012; Ghosh, 2015).

Therefore, the development of employees refers not just to the cognitive part but also includes the emotional. The employee, regardless of hierarchical level, evolves, not only gaining knowledge through formal education in order to fulfil the organization's mission but also through acquiring skills that will help him or her to grow internally, i.e., gain a deeper understanding of his or her position in the working group, to redefine his or her personal values and align them with the objectives of the organization (Furnham, 2012; Tran, 1998). Therefore, we can hypothesize the following:

$\mathbf{H}_{1}$ : Emotional intelligence affects the development of employees and their personal improvement

Other studies highlight that emotional intelligence at group level (group emotional intelligence) is positively correlated with the development of decision-making skills and problem solving within the group (Ghosh et al., 2012). The direct positive effect of emotional intelligence in the development of "the learning organization" is confirmed in the empirical research of public organizations by Danaeefard, Salehi, Hasiri, and Noruzi (2012). The strong positive effect of emotional intelligence on every aspect of the learning process in an organization is concluded in the research of Esfahani, Ordibehesht and Zolfaghari (2013). Earlier, Jordan (2004) theoretically demonstrated that the high emotional intelligence of the members of an organization contribute decisively to the improvement and development of all dimensions of "a learning organization".

Goleman (1998) suggested a holistic approach to emotional intelligence referring not only to individual skills that characterize it, but rather to the social dimension and collective dynamic which has much more importance when we refer to an entire organization. Since teamwork constitutes social activity, emotions at a group level hold a dominant role in understanding the parameters of working life. Emotional skills at group level contribute to the development of the social capital of an organization, in line with its cognitive and human capital (Goleman, 1998; Stubbs-Koman \& Wolff, 2008).

The upper hierarchical levels of management are responsible for creating an emotional climate where culture, objectives and employees are harmonized and aligned with the organization vision. A dynamic leadership is fully committed to the vision, creates a culture of continuous learning and improvement and on each occasion highlights the value and importance of change, development and growth. It achieves inspiration and confidence among employees in order to awaken them and to externalize their positive emotions. Thus employees understand how the organization operates and they perceive their exact position within it. It encourages employees to take on initiatives or actions because they feel like it and not because they are forced to do so. Employees feel valuable, believe in the values and mission of the organization, ensuring in this way the commitment to the common vision. Therefore, we can hypothesize the following:

$\mathbf{H}_{2}$ : Emotional climate affects the vision of the organization

The members of an organization should actively listen to this vision and common emotional climate which is created within the organization and should be based on the following factors: common values, shared motivation (objectives and needs), common beliefs and attitudes. The 
organizational reality and the sociability of the members contributes to this common emotional climate, transforming it each time in terms of quality and quantity, according to internal dynamic and external influences received by the organization (Hughes, 2000; Tran, 1998).

Work tasks are usually assigned to groups. The attitude and behaviour of each team member, as well as the interaction between these members, contribute to the optimal performance of these tasks. A determining factor in this whole process are the emotions, since all forms of interaction between team members produce emotions, which are contagious, spread throughout the group and influence members' attitudes. Collective emotional intelligence skills at group level build its social capital, produce attitudes and create new interactions. As the emotions of people within an organization are perceived at multiple levels, so group emotional intelligence exists in multiple levels and it is greater than the sum of the emotional intelligence of each member separately (Cote, 2007; Druskat \& Wolff, 2008). Therefore, we can hypothesize the following:

$\mathbf{H}_{3}$ : Work-group emotional intelligence affects employees' attitudes and behaviours

The creation, development and dynamics of the emotional climate that emerges in an organization has a tremendous impact on the learning process in this organization, whether positive or negative. The basic skills describing emotional intelligence, both at individual and work-group level, have an increasing influence on how employees work together in a team, how they learn and what they do. The emerging value of intellectual capital in the well-being of an organization makes the way in which its members acquire new knowledge, experience and skills, a decisive competitive labour market advantage (Goleman, 1995; Tran, 1998).

In addition, organizations have been experiencing rapid technological and structural changes over the last few decades, while the nature of work has shifted from assigning individual duties to collective assignment and responsibility at group level. Many researchers are addressing the question of whether these organizations, working through the work-groups, can achieve optimal performance through a collective learning process. The development of work skills at a group-level is the key to this equation and, especially, the creation of group emotional intelligence skills is at the forefront of prerequisites for a successful individual and collective learning process in an organization. The learning process is no longer meant only as a cognitive process, but also as an emotional process (Gabriel \& Griffiths, 2002; Ghosh et al., 2012).

Furthermore, the empirical research by Ghosh et al. (2012) proves that emotional intelligence, at group level in an organization, is strongly correlated with the learning process in these work-groups. Ghosh (2015), with a more recent empirical research, proves that emotional intelligence is positively correlated with every dimension of a "learning organization" and is one of the key factors influencing the process of establishing an organizational culture of learning that helps the organization to be able to adapt to continuous changes in the external environment. The same findings have been reported in the empirical studies of Singh (2007, as cited in Ghosh, 2015), Sanjay (2007, as cited in Ghosh, 2015) and Rafiq et al. (2007; 2011, as cited in Ghosh, 2015), that reinforce the belief that modern organizations, within a globalized environment, gain a strong competitive advantage when their members are distinguished for their high emotional intelligence. Therefore, we can hypothesize the following: 
H4: Work-group emotional intelligence affects the learning process within the group

The empirical research of Naseer, Chishti, Rahman and Jumanti (2011) conducted with the participation of many different work-groups, demonstrated the strong positive effect of emotional intelligence on the performance of these groups. The same research confirms the strong interdependence of emotional intelligence with the cognitive processes of information exchange and learning that take place in a group. Also, the empirical research of Dissanayaka, Janadari and Chathurani (2010) proves that emotional intelligence is a concept that emerges and takes place at multiple collective levels, connecting emotions with cognitive processes, which is a prerequisite for improving relationships and interactions among the members of a group.

Emotional intelligence is positively correlated with the development of healthy social behaviours and cooperative relationships. High emotional intelligence in a work-group implies the development of commonly accepted cognitive models, which in turn lead to sustainable processes of information and learning exchange within the group and the organization. The learning process in an organization has been found to be much more successful when it is promoted by members of work-groups with a high sense of emotional and social intelligence, as employees experience the emotional security offered by the work environment and are not afraid to exchange or receive information and share their previous experience. Groups with members of high emotional intelligence have greater potential to develop positive attitudes towards innovation, to generate new ideas and to discover new ways of managing issues and problems (Clarke, 2010; Dissanayaka et al., 2010).

This points towards a more flexible structure with fewer hierarchical levels, where with the use of appropriate information systems, the flow of information is facilitated and the members of the organization are better informed, having a more complete picture of the organization. The proper exchange of information constitutes a key endemic factor in the process of learning within an organization. High emotional intelligence facilitates this process by creating this organizational framework that promotes sincere and well-intentioned interaction among the members of a work-group (Clarke, 2010; Jordan, 2004). Therefore, we can hypothesize the following:

H5: Work-group emotional intelligence affects the diffusion of information within the group

\section{Research Methodology}

The present research was conducted among Greek Independent Administrative Authorities, a key area of Greek Public Administration, and aims to contribute to the fulfilment of the Greek Public Administration's transformation in the European context. It constitutes quantitative research and of the 300 questionnaires sent out, 257 were returned completed. Our sample of 257 respondents represents $14 \%$ of the total workforce employed in the above-mentioned public organizations.

The data collection of our research was initially based on 3 widely used and tested questionnaires following a careful selection of questions, which we consider to best serve our research objectives, at the same time meeting the basic principles of a questionnaire:

- Oudejans, S.C.C. (2009) 
- Watkins \& Marsick (1999)

- Jordan, P. and Lawrence, S. (2009)

More specifically, it is a short, structured questionnaire of 40 questions divided into 3 sections: The $1^{\text {st }}$ explores the degree of emotional intelligence of the members of the groups using a 5-point Likert scale, the second section studies the five dimensions of a Learning Organization according to Senge's Model as well as the effect of emotional intelligence at work-group level on these dimensions, and the last section contains questions related to demographic characteristics.

We ran a test reliability of the questionnaire (demographical data excluded) with SPSS 17.0, the internal consistency turned out to be excellent (Cronbach's Alpha: .94) and therefore we proceeded with the data processing.

\section{Results}

\section{Demographic Characteristics}

As shown in Figure 1, the vast majority reported their gender as female, while the most common ages fell between 31 and 54 years old. Moreover, the educational level is very high as almost $50 \%$ of the participants holds Masters or PhDs and only $16.3 \%$ have a secondary level education. Finally, the respondents have considerable working experience as $85.6 \%$ have already been working more than 11 years.

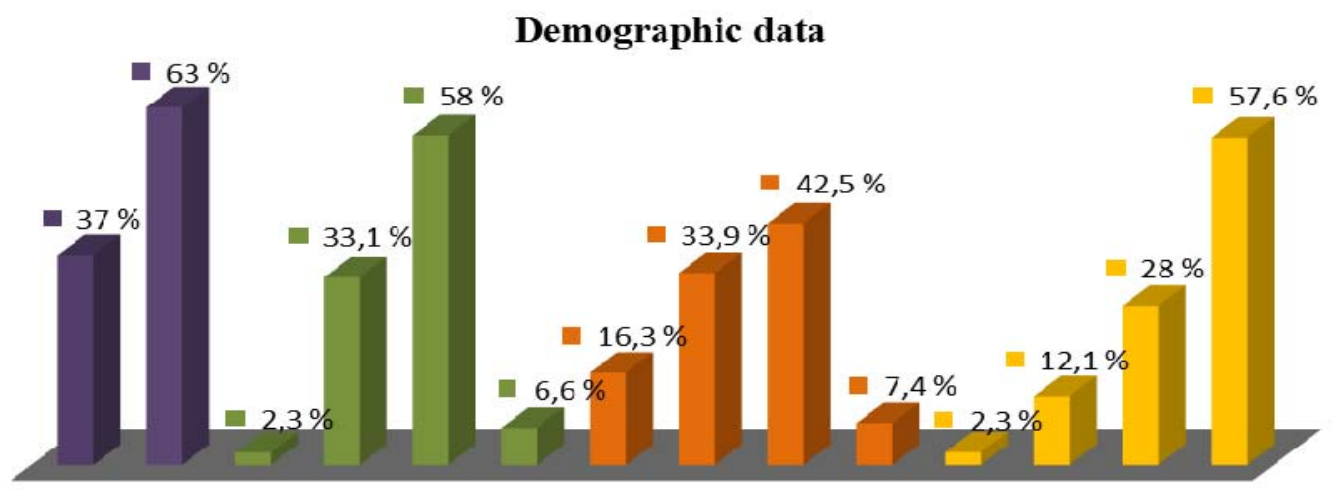

Figure 1. Demographic characteristics

\section{Main Findings and Hypothesis Testing}

The mean values of responses regarding emotional intelligence recorded quite high scores which were well above average as shown in Figure 2. The variables "I have a good understanding of the emotions of the people around me", "I am sensitive to the feelings and emotions of others" and "I always know my team members' emotions from their behaviour" presented the highest values, 4.36, 4.25 and 4.16 respectively, while the variables "I really understand what I feel" and "I always know whether or not I am happy" scored the lowest values, 2.98 and 2.89 respectively (Figure 2). 


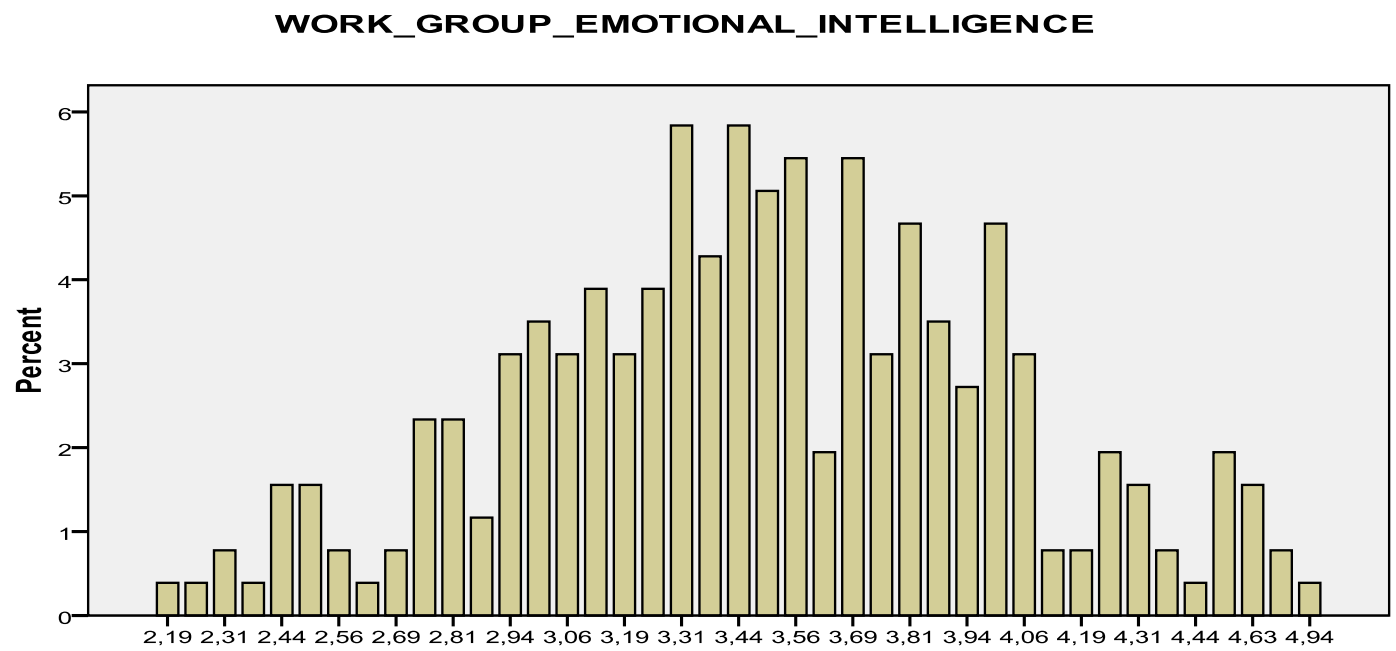

WORK_GROUP_EMOTIONAL_INTELLIGENCE

Figure 2. Work-group emotional intelligence

Other significant findings from the analysis are related to the participants' perceptions towards the learning organization dimensions. More specifically, the mean of participants' responses emphasizes their perception that emotional intelligence has an impact mainly on personal improvement $(M=3.52)$ and to a lesser extent on information diffusion $(M=3.07)$. In addition, considering the other dimensions of the learning organization, learning process $(M=$ $3.12)$, attitudes and behaviours $(M=3.34)$ and vision of the organization $(M=3.42)$, the mean values slightly deviate from each other but remain above the average (Figure 3).

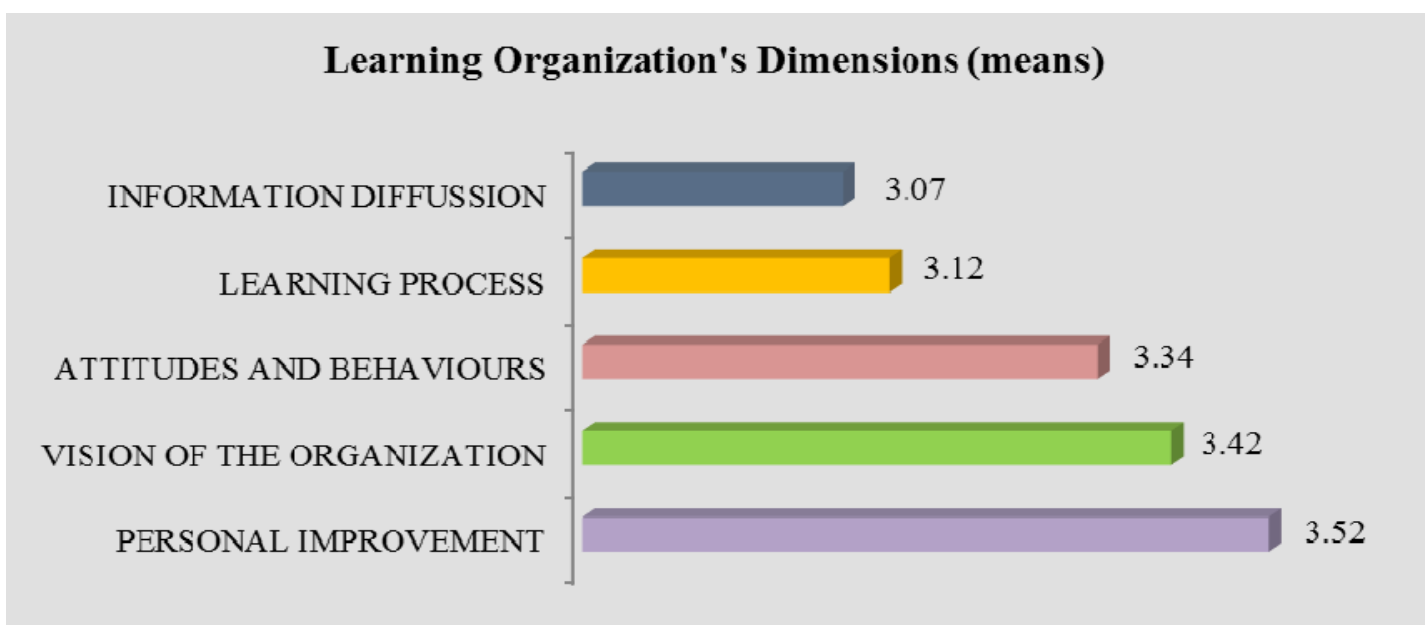

Figure 3. Learning organization's dimensions

One-way analysis of variance (ANOVA) was run for testing all the hypotheses and for each item separately. The results for each hypothesis are examined and presented in greater detail in the following paragraphs.

$\mathbf{H}_{1}$ : Emotional intelligence affects the development of employees and their personal improvement 
The results strongly confirm $\mathrm{H}_{1}$ as 4 out of 4 items appear to be of great significance as shown below:

Table 1

Exploration of $\mathrm{H}_{1}$

\begin{tabular}{lc}
\hline \multicolumn{1}{c}{ Item } & $p$ \\
\hline I can exert a great deal of influence on improving how I do my job. & .001 \\
\hline I feel responsible for the achievement of good results. & .001 \\
I perceive how my job contributes to the achievement of the organization's goals. & .001 \\
I have spent time in the past month updating my knowledge and skills. & .009 \\
\hline
\end{tabular}

$\mathrm{H}_{1}$ is related to personal mastery, and the way employees feel about their tasks and responsibilities reflects their perception and attitude towards themselves firstly and the organization secondly. Moreover, in combination with the relevant descriptive statistics shown above, employees are of higher than average emotional intelligence, and not only are they interested in personal mastery, but they also make efforts in this direction.

$\mathbf{H}_{2}$ : Emotional climate affects the vision of the organization

Based on one-way ANOVA test, $\mathrm{H}_{2}$ is also strongly confirmed as all items related to this hypothesis record strong significant levels as shown in Table 2.

Table 2

Exploration of $\mathrm{H}_{2}$

\begin{tabular}{lc}
\hline \multicolumn{1}{c}{ Item } & $p$ \\
\hline I feel closely involved with my organization. & .001 \\
\hline $\begin{array}{l}\text { Employees are motivated and determined } \\
\text { to achieve the vision and common objectives. }\end{array}$ & .001 \\
\hline $\begin{array}{l}\text { My organization invites employees to contribute } \\
\text { to the organization's vision. }\end{array}$ & .001 \\
\hline My colleagues spend time building trust with each other. & .001 \\
\hline
\end{tabular}

$\mathrm{H}_{2}$ refers to the shared vision of the organization. Having achieved the development of an emotional climate that inspires confidence and gives emphasis to values, employees feel valuable and they are firmly committed to the organization's vision.

$\mathbf{H}_{3}$ : Group emotional intelligence affects employees' attitudes and behaviours

As presented in Table $3, \mathrm{H}_{3}$ is also confirmed as all items included in this hypothesis present statistically acceptable correlations $(p<.05)$. Variable "My colleagues help each other learn" presented a less strong correlation $(p=.04)$, slightly below .05.

Table 3

Exploration of $\mathrm{H}_{3}$ 
My colleagues openly discuss mistakes in order to learn from them

.001

My colleagues are given time to support learning

.001

My colleagues treat each other with respect

.004

My colleagues help each other learn

.041

$\mathrm{H}_{3}$ is related to mental models. The analysis found that emotional intelligence has an impact on positive attitudes and behaviours of the employees. Therefore, it is very important that emotionally intelligent employees foster teamwork, prevent and isolate any potential conflict behaviour and are given adequate time to help their colleagues.

$\mathbf{H}_{4}$ : Work-group emotional intelligence affects the learning process within the group

The analysis (one-way Anova) presents a high correlation between work-group emotional intelligence and learning process as all relevant variables were found to be of high statistical significance, as indicated in Table 4.

Table 4

Exploration of $\mathrm{H}_{4}$

\begin{tabular}{ll}
\hline Item & $p$ \\
\hline In my organization, teams revise their thinking as a result of group discussion or information collected & .001 \\
In my organization teams have the freedom to adapt their goals as needed & .001 \\
The members of my team give each other open and honest feedback at official meetings & .001 \\
Teams are rewarded for their team achievements & .002 \\
\hline
\end{tabular}

$\mathrm{H}_{4}$ refers to team learning and from the above results it is confirmed that work-group emotional intelligence makes employees more adaptable and flexible, facilitating in this way the learning process within the team.

H5: Work-group emotional intelligence affects the diffusion of information within the group

Data analysis also confirmed the last hypothesis. In particular, 2 out of 4 items recorded very strong correlations (access to needed information and recognition of taking initiatives) while "the desire to learn and share information is taken into consideration when promoting" appeared to be slightly less strongly correlated, as displayed in Table 5.

Table 5

Exploration of $\mathrm{H}_{5}$

\begin{tabular}{ll}
\hline \multicolumn{1}{c}{ Item } & $p$ \\
\hline My organization enables people to get needed information at any time quickly and easily & .001 \\
\hline My organization recognizes people for taking initiatives & .001 \\
\hline New employees are encouraged to explore the current practices at organizational level & .002 \\
When promoting the desire to learn and share information is taken into consideration & .002 \\
\hline
\end{tabular}

$\mathrm{H}_{5}$ is related to systems thinking as the organization facilitates and encourages the flow of information through its updated procedures and it's less hierarchical structures.

\section{Results and Discussion}


The importance of this research lies in the fact that it highlights the effect of collective emotional intelligence, through the constructive emotional climate it creates, on the development of organizational learning. In other words, this research has confirmed that workgroup emotional intelligence in Independent Administrative Authorities of the Greek Public Administration is one of the key factors for creating learning teams and learning organizations.

The present research aimed to determine whether work-group emotional intelligence affects the dimensions that make up the meaning of the learning organization according to Senge (1990, as cited in Jordan, 2004). The results showed that work-group emotional intelligence in Greek Independent Administrative Authorities is at a high level and similarly the means of each dimension of the concept of learning organization are also high. The findings showed that work-group emotional intelligence is strongly associated with every dimension of the learning organization in the relevant organizations. It has been found that work-group emotional intelligence is directly linked and strongly influences the personal improvement and development of employees, the process of group learning, the process of diffusing information within the group and the structures of the organization involved in that learning process. It also strongly influences employees' attitudes and behaviours, as well as the shaping of a common vision within the organization.

Work-group emotional intelligence is also featured as an important factor that is strongly related to significant work-group processes, such as communication, work collaboration, interpersonal relationships, conflict management, employee engagement and participation, decision-making processes and above all affects the learning process at an individual, team and organizational level (Clarke, 2010; Hughes, 2000).

Moreover, high emotional intelligence in work-groups helps their members engage in constructive discussions, interactions and exchanges, creating a productive learning environment and climate that leads to creativity, innovation and higher performance. Emotional intelligence provides team members with the ability to understand emotions and use them to facilitate the learning process, either at an individual or group level, resulting in the creation of a potential strategic advantage for the organization (Ghosh et al., 2012; Stubbs-Koman \& Wolff, 2008).

The relationship between work-group emotional intelligence and the dimensions of the learning organization is direct and strong thus verifying the existing literature and making it easier for the organization to develop into a learning organization (Danaeefard et al., 2012; Dissanayaka et al., 2010; Esfahani et al., 2013; Ghosh et al., 2012, 2015; Jordan et al., 2002; Stubbs-Koman \& Wolff, 2008).

\section{Implications and Suggestions}

First of all, an organization's leadership should be committed to the development of a climate that promotes emotional intelligence, at individual and group level, enhances mutual trust and appropriate learning behaviours, leading to the overcoming of the aforementioned obstacles.

In accepting that intellectual capital is the most valuable resource of the organization; managers should be focused to develop more emotionally intelligent members by cultivating an environment that facilitates this goal. In addition, they are responsible for creating a constructive emotional climate within the organization, resulting in the development of positive 
organizational behaviours and establishing mental models that promote systemic thinking and group learning. Moreover, managers should be genuinely interested in employees' opinions, encourage the existence of many different opinions, free from any criticism and adopt active listening. Managers in a learning organization promote dialogue and have time and resources to create and maintain an environment where the whole process of transforming an organization into a learning organization will thrive.

To this end, managers should take on initiatives/activities where the members of the groups are brought together, helping them to get to know each other, exchange experiences, share knowledge, develop new ideas, share common visions and focus on common goals. The introduction of emotional learning programmes in the organization can help employees and work-groups to develop sufficient knowledge of the importance of this issue. Emotional intelligence training can help employees and managers acquire the appropriate emotional intelligence skills leading to the building of such a group-level emotional intelligence that will contribute to better communication between work-groups, better management and development of knowledge and higher efficiency for the organization.

Emotional intelligence, as well as the learning process in the organization, must be treated by managers as collective processes and not just on an individual level, since this collective dynamic creates the maximum correlation between these two concepts and brings the most benefit to the organization.

The present study, like all research, cannot escape the rule of restrictions. The present research was conducted in a particular sector of the Greek Public Administration, that of Independent Administrative Authorities. The Greek Independent Administrative Authorities benefit from a highly skilled human resource of a relatively young age with above-average qualifications for the Greek civil servant and, therefore, in order for our results to be generalized, research should also be extended to other sectors of the Greek Public Administration, using random sampling and covering the country as a whole.

Since other personal or organizational factors are not taken into consideration in our study, in future research, other factors that play a role in shaping the relationship between work-group emotional intelligence and learning organization in the workplace could be further explored, such as employee's personality, organizational culture and hierarchy levels.

\section{References}

Barrados, M., \& Mayne, J. (2003). Can public sector organisations learn? OECD Journal on Budgeting, 3(3), 87-136.

Bergiel, B. J., Bergiel, E. B., \& VBalsmeir, P. W. (2008). Nature of virtual teams: a summary of their advantages and disadvantages. Management Research News, 31(2), 99-110.

Bordeianu, O., Hapenciuc, C. V., Bejinaru, R., \& Burciu, A. (2014). Dimensions of the learning organization within pharmaceutical companies in Romania. Proceedings of the $8^{\text {th }}$ International Management Conference Management Challenges for sustainable development (pp. 605-616), Bucharest, Romania.

Chawla, S., \& Renesch, J. (1995). Learning organizations: Developing cultures for tomorrow's workplace. Portland, OR: Productivity Press.

Clarke, N. (2010). Emotional intelligence and learning in teams. Journal of Workplace Learning, 22(3), 125-145.

Cote, S. (2007). Group emotional intelligence and group performance. In M. Neale, E. Mannix, \& C. Anderson (Eds.), Research on managing groups and teams: Affect and groups (pp. 309-336). Oxford, UK: Elsevier JAI.

Danaeefard, H., Salehi, A., Hasiri, A., \& Noruzi, M. (2012). How emotional intelligence and organizational culture contribute to shaping learning organization in public service organizations. African Journal of Business Management, 6(5), $1921-1931$. 
Daryani, S. M., Ardabili, F. S., \& Amini, M. (2014). The study models of learning organisation building. International Journal of Learning and Intellectual Capital 1, 11(4), 320-333.

Dissanayaka, D., Janadari, M., \& Chathurani, R. (2010). Role of emotional intelligence in organizational learning: An empirical study based on banking sector in Sri lanka. Proceedings of the 2nd International Conference on Business and Information (pp. 1-23). University of Kelaniya, Sri Lanka.

Druskat, V., \& Wolff, S. (2008). Group-level emotional intelligence. In N. Ashkanasy, \& C. Cooper (Eds.), Research companion to emotion in organizations (pp. 441-454). Cheltenham, London: Edward Elgar.

Esfahani, M., Ordibehesht, M., \& Zolfaghari, F. (2013). Study of the relationship between knowledge and emotional intelligence; case study: Melli bank of Qom. International Research Journal of Applied and Basic Sciences, 4(8), 21002106.

Furnham, A. (2012). Emotional intelligence. Research Department of Clinical, Educational and Health Psychology, University College London. Retrieved from $<$ http://cdn.intechopen.com/pdfs-wm/27237.pdf $>$ [accessed 19/08/2017].

Gabriel, Y., \& Griffiths, D. (2002). Emotion, learning and organizing. The Learning Organization, 9(5), 214-221.

Garvin, A. D., Edmondson, C. A., \& Gino, F. (2008). Is yours a learning organization?" Harvard Business Review Knowledge Management. Retrieved from: < https://hbr.org/2008/03/is-yours-a-learning-organization>

Ghosh, N. (2015). Emotional intelligence: A critical dimension of learning organisations. Proceedings of the Twelfth AIMS International Conference on Management, Indian Institute of Management, Kozhikode.

Ghosh, R., Shuck, B., \& Petrosko, J. (2012). Emotional intelligence and organizational learning in work teams. Journal of Management Development, 31(6), 603-619.

Gilson, C., Dunleavy, P., \& Tinkler, J. (2009). Organizational learning in government sector organizations: literature review. LSE Public Policy Group (PPG), 1-43.

Goleman, D. (1995). Emotional intelligence. New York, NY: Bantam Books

Goleman, D. (1998). Working with emotional intelligence. London, UK: Bloomsbury Publishing.

Hughes, J. (2000). the learning organisation part ii, 'getting emotional': The learning organisation and emotional intelligence. Centre for Labour Market Studies, University of Leicester, Working Paper, 31, 1-17.

Jordan, P. (2004). Dealing with organisational change: Can emotional intelligence enhance organisational learning? International Journal of Organisational Behaviour, 8(1), 456-471.

Jordan, P., Ashkanasy, N., Hartel, C., \& Hooper, G. (2002). Workgroup emotional intelligence scale development and relationship to team process effectiveness and goal focus. Human Resource Management Review, 12(2), 195-214.

Jordan, P., \& Lawrence, S. (2009). Emotional intelligence in teams: Development and initial validation of the short version of the Workgroup Emotional Intelligence Profile (WEIP-S). Journal of Management and Organization, 15(4), 452-469.

Langley, A. 2000. "Emotional Intelligence - a new evaluation for management development?", Career Development International, 5(3), 177-183.

Mayer, J., \& Salovey, P. (1997). What is emotional intelligence?” In P. Salovey, \& D. Sluyter (Eds.), Emotional development and emotional intelligence: Implications for educators (pp. 3-31). New York, NY: Basic Books.

Moynihan, P. D., \& Landuyt, N. (2009). How do public organizations learn? bridging cultural and structural perspectives. Public Administration Review, 69(6), 1097-1105.

Naseer, Z., Chishti, S., Rahman, F., \& Jumanti, N. (2011). Impact of emotional intelligence in team performance in higher education institutes. International Online Journal of Educational Sciences, 3(1), 30-46.

O'Keefee, T. (2002). Organizational learning: A new perspective. Journal of European Industrial Training, 26(2), $130-141$.

Oudejans, S. C. C. (2009). Routine outcome monitoring \& learning organizations in substance abuse treatment. Amsterdam: Universiteit van Amsterdam [Host].

Pedler, M., Burgogyne, J., \& Boydell, T. (1997). The learning company: A strategy for sustainable development. $2^{\text {nd }}$ Ed. London: McGraw-Hill.

Public Service Agency, Canada. (2007). A primer on the learning organization. Retrieved from < https://www.tbssct.gc.ca/dev/dwnld/lapn-eng.pdf $>$.

Salovey, P., \& Mayer, J. (1990). Emotional intelligence. Imagination, Cognition and Personality, 9(3), 185-211.

Stubbs-Koman, E., \& Wolff, S. (2008). Emotional intelligence competencies in the team and team leader: A multi-level examination of the impact of emotional intelligence on team performance. Journal of Management Development, 27(1), 5575 . 
Tran, V. (1998). The role of the emotional climate in learning organisations. The Learning Organization, 5(2), 99-103.

Visser, M., \& Van der Togt, K. (2015). Learning in public sector organizations: A theory of action approach. Public Organization Review, 16(2), 235-249.

Watkins, K. E., \& Marsick, J. V. (1999). Dimensions of the learning organization questionnaire: Introduction. Retrieved from $<\mathrm{http}$ ://www.partnersforlearning.com/questions.php $>$ [accessed 10/09/2017].

Yosoff, M. S. B. M. (2005). The public service as a learning organization. International Review of Administrative Sciences, 71(3), 463-474. 